\title{
No Effect of Intra-Articular Platelet-Rich Plasma Injections after Arthroscopic Repair of Rotator Cuff Tears: a Prospective Randomized Study
}

\author{
J. R. Almoguera Sánchez-Villacañas' ${ }^{1}$ A. Almoguera-Martinez², G. H. Seoane ${ }^{1}$, \\ Á. Sutil Blanco ${ }^{1}$, C. I. Godinho-Soares², F. García De Lucas ${ }^{1}$ \\ 1 FREMAP Mutua Accidentes Laborales Hospital, Majadahonda, Madrid, Spain \\ 2 Príncipe De Asturias Hospital, Alcalá De Henares, Madrid, Spain
}

\author{
CORRESPONDING AUTHOR: \\ Alejandro Almoguera-Martinez \\ Príncipe De Asturias Hospital \\ Alcalá De Henares, Madrid, Spain \\ Calle Buganvilla 6 \\ 28036 Madrid, Spain \\ E-mail: Jandro_Am@Hotmail.com \\ DOI:
}

10.32098/mltj.03.2021.23

LEVEL OF EVIDENCE: $1 B$

\begin{abstract}
SUMMARY
Background. Our study aims to evaluate the results of platelet-rich plasma (PRP) infiltration after arthroscopic repair of the rotator cuff.

Methods. We carried out a randomized simple blind clinical trial with an initial sample of 38 patients. Of those, three were excluded intraoperatively. These patients were assigned into two groups: rotator cuff suture with PRP administration $(\mathrm{n}=17)$ and rotator cuff suture without PRP administration $(n=18)$. Intraoperatively, we excluded all massive tears, i.e., those with more than $3 \mathrm{~cm}$ retraction or affecting more than two tendons, Snyder type C4 or Patte grade III.

We performed clinical and radiological evaluations at the $2^{\text {nd }}$ and $6^{\text {th }}$ week, $3^{\text {rd }}$ and $6^{\text {th }}$ month, and the last assessment at the $1^{\text {st }}$ year.

Results. We did not demonstrate statistically significant differences comparing measurements, clinical scales applied (AVS scale, DASH, Constant-Murley, Shoulder test, UCLA test, and shoulder range of motion) during the follow-up period, and radiological findings between both groups.

Conclusions. Several research studies have shown PRP efficacy in injured tendons and ligaments. Some of them have even obtained satisfactory clinical results applied in rotator cuff repair, whereas others, including ours, have not shown statistically significant clinical improvement.
\end{abstract}

KEY WORDS

Arthroscopy; clinical outcome; Platelet-Rich Plasma; rotator cuff repair; shoulder.

\section{BACKGROUND}

Platelet-Rich Plasma (PRP) is an autologous biologic material, obtained through centrifugation of the patient peripheral venous blood sample. Aside from their role in coagulation, platelets have an array of growth factors crucial to the healing process of both tendons and cartilage, both with a poor intrinsic capacity of regeneration due to their precarious blood supply $(1,2)$.

Though on itself arthroscopic treatment of rotator cuff tears presents excellent outcomes, retear rate is not negligible, being greater than $25 \%$ in some series (3). An important cause of retear is, precisely, tendons' low regenerative capac- ity $(4,5)$, since they do not recover their normal characteristics, their insertion relying on scar tissue (6) with significantly less biomechanical strength (7).

Several research studies have shown PRP efficacy in injured tendons and ligaments (8-11); however, the efficacy of PRP treatment on injured tendons is highly controversial (12).

Some of them have even obtained satisfactory clinical results applied in rotator cuff repair $(13,14)$, whereas others have not shown statistically significant clinical improvement $(15,16)$.

Therefore, our study aims to evaluate the results of PRP infiltration after arthroscopic repair of the rotator cuff. 


\section{MATERIALS AND METHODS}

We have carried out a randomized simple blind clinical trial in our centre with an initial sample of 38 patients. Of those, 3 were excluded intraoperatively. This work was approved both by the centre's ethical committee and the Instituto Nacional de Salud. All surgical procedures were carried out by the same surgeon (J. R. A) from January 2012 to December 2018. This study follows the ethical international standards as described by Padulo et al. (17). The cases were selected according to the following inclusion criteria:

- patients under the age of 60 years old, diagnosed both clinically and through magnetic resonance imaging (MRI) with a rotator cuff tear, and had been treated conservatively for at least 3 months;

- patients with tears that were considered reparable a priori, i.e., full-thickness supraspinatus tendon tears with 2 to $3 \mathrm{~cm}$ retraction and Snyder type C2 or C3 or Patte grade I or II;

- furthermore, fatty infiltration of the muscle was assessed with MRI, using Fusch et al. classification (modified by Goutalier et al), including solely grades 1 and 2 of this classification;

- cases with the following exclusion criteria were discharged;

- long bicipital head tendon instability;

- intra-articular pathology of the labrum;

- glenohumeral and acromioclavicular osteoarthritis;

- shoulder stiffness associated with capsulitis;

- patients with previous surgery of that shoulder;

- patients who had received corticosteroid infiltration less than 6 weeks before the study;

- severe and limiting pathology of other articulations of the superior extremity;

- partial or exclusive subscapular tears;

- acute tears less than 6 weeks before the study;

- massive tears, i.e., those with more than $3 \mathrm{~cm}$ of retraction or affecting more than 2 tendons, Snyder type C4 or Patte grade III;

- Fusch grade 3: equal amount of fatty and muscular tissue or more fat than muscle (equivalent to Goutalier grade III-IV).

Despite these criteria, patients were not definitively included in this study until the characteristics of the tear were verified intraoperatively.

Patients that presented any of the following medical criteria were also excluded:

- type I or II diabetes;

- smokers;
- BMI greater than 33;

- presence of neuromuscular disease;

- evidence of both acute or chronic infectious disease;

- presence of known hematologic or coagulation disease;

- patients with less than 150000 total platelets or less than $12 \mathrm{~g} / \mathrm{dL}$ haemoglobin in blood;

- plasmatic fibrinogen level below $150 \mathrm{mg} / \mathrm{dL}$ or greater than $450 \mathrm{mg} / \mathrm{dL}$;

- total protein plasmatic level below $6 \mathrm{~g} / \mathrm{dL}$ or greater than $8.4 \mathrm{~g} / \mathrm{dL}$.

All patients that met the inclusion criteria were submitted to a pre-surgical study, which included the data below:

- shoulder range of motion (flexion, abduction, and rotations);

- pain intensity (AVS scale);

- constant scale (filled by the researcher);

- simple and oblique shoulder x-rays;

- MRI. Sagittal, oblique, coronal oblique and axial cuts were used, bearing in mind the inclusion criteria described earlier in this paper.

Once the patients were included in the study they signed the informed consent for both surgical treatment and their participation in this study. Then a third party, unrelated to this study (a nurse professional), carried out the randomization process. This person would select an opaque and sealed envelope where each patient was assigned to either group:

- GROUP I: rotator cuff suture WITHPRP administration;

- GROUP II: rotator cuff suture WITHOUT PRP administration.

Anaesthesia was performed with interscalene block and general anaesthesia. The patient was positioned in lateral decubitus using Arthrex traction system with $30^{\circ}$ abduction and $30^{\circ}$ anterior flexion via 3 and $2 \mathrm{~kg}$, respectively. Diagnostic arthroscopy was then carried out, using $30^{\circ}$ lenses and an irrigation pump controlled at $50 \mathrm{mmHG}$. The usual and necessary portals were used according to the tear type, this being identified between both spaces. If the tear did not meet the inclusion criteria the patient was excluded from the study.

All repairing procedures were carried out standardly, the surgeon's usual technique consisting of single-row direct lateral repair. In all cases, and depending on bone quality, either $5.5 \mathrm{~mm}$ or $6.5 \mathrm{~mm}$ Arthrex Biocork-Screw bioabsorbable anchors were used. A standard uniform acromioplasty was performed in all patients.

Intraoperatively, we excluded all massive tears, i.e., those with more than $3 \mathrm{~cm}$ retraction or affecting more than 2 tendons, Snyder type C4 or Patte grade III. 
A peripheral venous blood sample was extracted from the patients who met the inclusion criteria and who had been assigned randomly to the group I of this study. A platelet concentrate was prepared from this sample, always taking into account the procedure explained in BIOMET's GPS/ RECOVER $^{\circledR}$ III Simple $(6 \mathrm{ml})$ 800-0675A disposable kit. We used Pure Platelet Rich Plasma (P-PRP), according to Dohan Ehrenfest et al. classification (18).

Once the repair was completed, traction was removed and suture stability was then checked. Using a lateral portal, the team placed an abbocath needle between the bone and the repaired tendon, so that the infiltration would be deposited on the insertion footprint. With the abbocath needle in place, the authors sucked out the irrigation fluid and took out the cannulas. Then, they slowly instilled the PRP, carefully avoiding extravasation. 50\% of the PRP was applied in the foot-print, which corresponds to the articular portion of the repaired tendon, and, retracting the abbocath needle, another $50 \%$ over the corresponding repaired tendon bursal face. 5 minutes after the injection was completed, $100 \mathrm{cc}$ of air were injected through a syringe to carry out a dry arthroscopy and assess PRP cloth development. Thus the procedure was considered completed, once all portals were closed and the arm was immobilized with a sling.

The patients' stay varied roughly from 24 to $48 \mathrm{~h}$, depending on their pain. A standard rehabilitation protocol was established for all patients included in the study, despite their group. During the first two weeks, the patient was allowed to execute passive motion and exercises that were not against gravity with the affected shoulder.

Active motion started between the $3^{\text {rd }}$ and $4^{\text {th }}$ week, according to the tear type, tissue quality, and suture.

The authors performed clinical evaluations at the $2^{\text {nd }}$ and $6^{\text {th }}$ week, $3^{\text {rd }}$ and $6^{\text {th }}$ month, and the last assessment at the $1^{\text {st }}$ year. In these visits, an independent researcher observed the following:

- at the $2^{\text {nd }}$ and ${ }^{\text {th }}$ week and the $3^{\text {rd }}$ month if there were any complications, AVS scale, ROM, and Constant score, adjusted by age and sex;

- at the $6^{\text {th }}$ month and the $1^{\text {st }}$ year DASH superior extremity function surveys, resting and active AVS scale, STT (Simple Shoulder Test), Constant score, and UCLA Shoulder Rating scale (all of them obtained from www. orthopaedicscores.com).

In regards to radiological evaluation, we carried out an ultrasound at the $3^{\text {rd }}$ and $6^{\text {th }}$ month after surgery, assessing the suture's integrity, and an MRI at the $12^{\text {th }}$ month, to assess tendon's integrity and occurrence of re-tear. These studies were performed blindly by a radiologist specialized in musculoskeletal pathology.

\section{RESULTS}

Of an initial sample of 38 patients, 3 were excluded intraoperatively due to the tear's characteristics. Thus, to the described results we are taking into account 35 patients, 17 of them in the group treated with PRP (Group I) and 18 in the group without PRP (Group II).

The patients had a mean age of 53.03 years old ( 7.524 years old), ranging between 33 and 66 years old, all of them at working age. In group I patients' mean age was 53.71 years old $( \pm 4.634$ years old $)$ and in group II 52.39 years old $( \pm 9.599$ years old $)$.

23 male $(65.7 \%)$ and 12 female $(34.3 \%)$ patients were included, group I composed by 9 male $(52.9 \%)$ and 8 female $(47.1 \%)$ patients and group II by 14 male (77.8\%) and 4 female $(22.2 \%)$ patients (figure 1).

Fourteen patients were high physical demand workers (40.0\%), 19 medium demand $(54.3 \%)$ and 2 patients were low demand $(5.7 \%)$. In Group I there were 5 high physical demand workers $(29.4 \%), 11$ medium demand $(64.7 \%)$, and 1 low demand worker $(5.9 \%)$. In group II there were 9 high physical demand workers (50\%), 8 medium demand $(44.4 \%)$, and 1 low demand worker (5.6\%) (figure 2 ).

In 27 cases $(77.1 \%)$ the right shoulder was the injured extremity, whereas in 8 cases $(22.9 \%)$ it was the left one. In group I, there were 11 cases of right shoulder injury $(64.7 \%)$ and 6 of left shoulder one $(35.3 \%)$, while in group II there

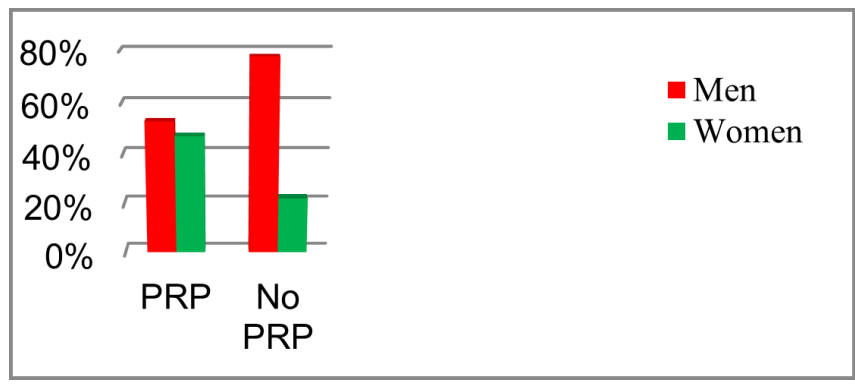

Figure 1. Sex distribution in both study groups.

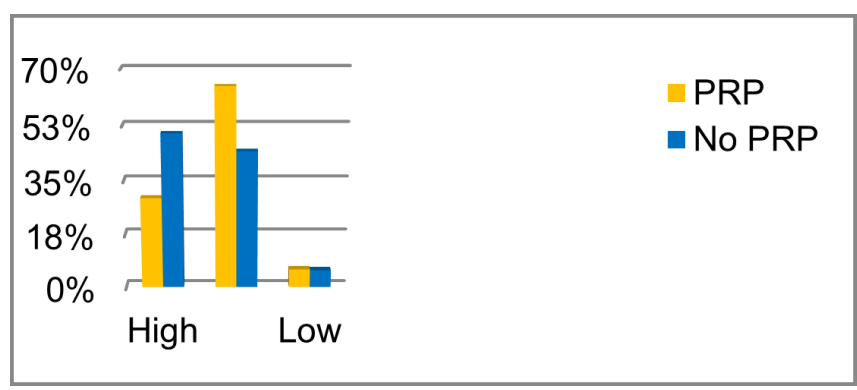

Figure 2. Physical work demand distribution in both study groups. 


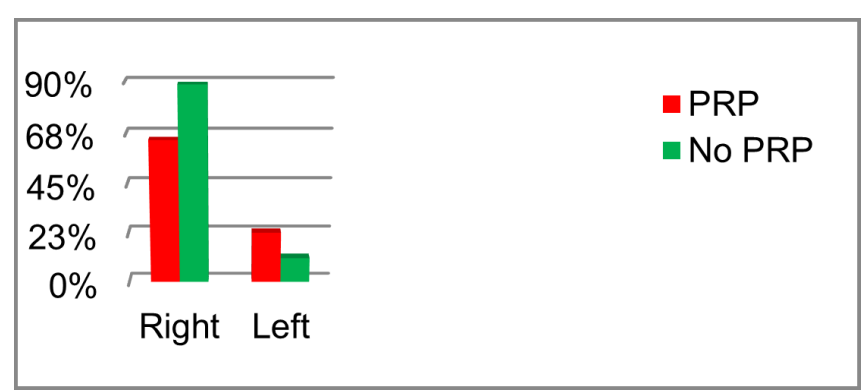

Figure 3. Affected side distribution in both study groups.

were 16 cases of right shoulder injury $(88.9 \%)$ and 2 cases of left shoulder injury (11.1\%) (figure 3).

Mean patients' sick leave was 38.2 weeks ( \pm 17.844 weeks), ranging from 12 to 96 weeks, the group I mean sick leave being of 40.53 weeks $( \pm 16.455$ weeks $)$ and 36 weeks ( \pm 19.272 weeks) in group II, without significant difference between both groups ( $p=0.261$ ) (Mann-Whitney U test).

The authors compared both AVS scale results during the development of the study. They also compared DASH results at 6 and 12 months of follow-up, with the following results (Mann-Whitney U test) (table I).

These authors also compared Constant-Murley results during the study from both groups. Shoulder test and UCLA test results at 6 and 12 months of follow-up were also compared, with the following results (Mann-Whitney U test) (table II).
We compared the shoulder's flexion and abduction evolution through the follow-up period, with the results shown below (Mann-Whitney U test) (table III).

These authors registered the following qualitative measures to assess shoulder internal rotation, from lesser to greater rotation: thigh, buttock, sacroiliac joint, waist, hand to T12 or lumbosacral pivot point, and between scapulae or complete intern rotation. To contrast the results a Chi-square test was applied, with comparisons made at all follow-up periods:

- pre-surgery evaluation: there were not found statistically significant differences between both groups in regards to internal rotation $(\mathrm{p}=0.187)$;

- there were no statistically significant differences at 3 weeks $(\mathrm{p}=0.690), 6$ weeks $(\mathrm{p}=0.213), 3$ months $(\mathrm{p}=0.109), 6$ months $(\mathrm{p}=0.710)$, or at 1 year $(\mathrm{p}=0.326)$ after surgery.

To assess the shoulder's external rotation, the following qualitative measures were registered from lesser to greater rotation: hand to nape, hand behind the head with elbows forward, hand behind the head with elbows back, and complete shoulder elevation. To contrast the results a Chi-square test was applied, with comparisons made at all follow-up periods:

- pre-surgery evaluation: there were not found statistically significant differences between both groups in regards to external rotation $(\mathrm{p}=0.186)$;

Table I. Comparison of Analogical Visual Scale (AVS) and DASH results in both study groups.

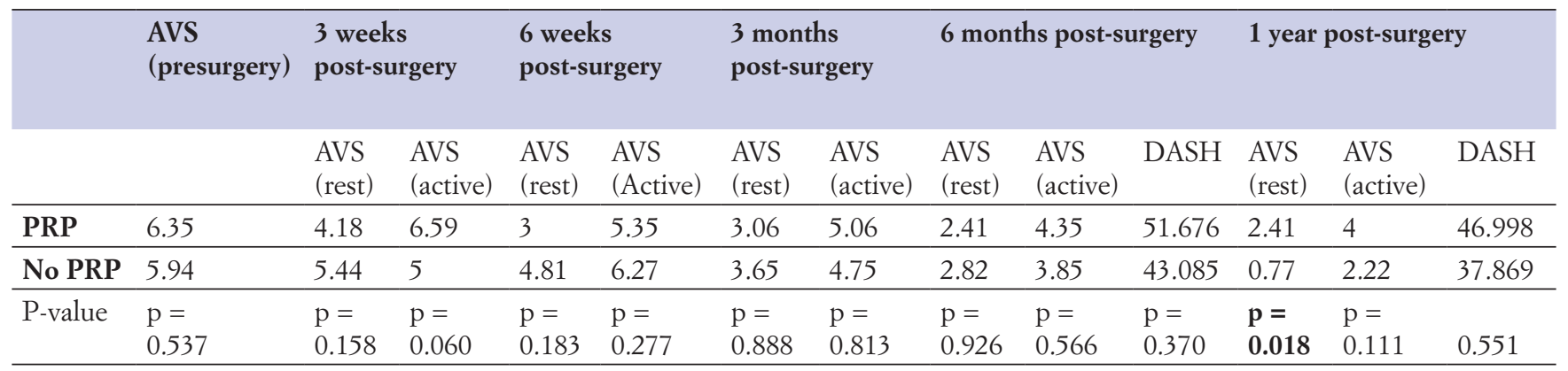

Table II. Comparison of Constant-Murley, Shoulder, and UCLA test in both study groups.

\begin{tabular}{|c|c|c|c|c|c|c|c|c|c|c|}
\hline & \multirow[b]{2}{*}{$\begin{array}{l}\text { Constant } \\
\text { (pre-surgery) }\end{array}$} & \multirow[b]{2}{*}{$\begin{array}{l}\text { Constant } \\
3 \text { weeks }\end{array}$} & \multirow[b]{2}{*}{$\begin{array}{l}\text { Constant } \\
6 \text { weeks }\end{array}$} & \multirow[b]{2}{*}{$\begin{array}{l}\text { Constant } \\
3 \text { months }\end{array}$} & \multicolumn{3}{|l|}{6 months } & \multicolumn{3}{|l|}{1 year } \\
\hline & & & & & Constant & Shoulder & UCLA & Constant & Shoulder & UCLA \\
\hline PRP & 64.073 & 34.412 & 50.912 & 69.765 & 67.294 & 51.859 & 23.18 & 70.071 & 59.135 & 24.41 \\
\hline No PRP & 51.8 & 39.194 & 65.964 & 77.563 & 75.971 & 51.8 & 26.75 & 86.179 & 64.75 & 26.47 \\
\hline P-value & $\begin{array}{l}p= \\
0.038\end{array}$ & $\begin{array}{l}\mathrm{p}= \\
0.478\end{array}$ & $\begin{array}{l}p= \\
0.047\end{array}$ & $\begin{array}{l}\mathrm{p}= \\
0.117\end{array}$ & $\begin{array}{l}\mathrm{p}= \\
0.202\end{array}$ & $\begin{array}{l}\mathrm{p}= \\
0.849\end{array}$ & $\begin{array}{l}\mathrm{p}= \\
0.134\end{array}$ & $\begin{array}{l}p= \\
0.030\end{array}$ & $\begin{array}{l}p= \\
0.629\end{array}$ & $\begin{array}{l}\mathrm{p}= \\
0.427\end{array}$ \\
\hline
\end{tabular}


Table III. Comparison of shoulder flexion and abduction in both study groups.

\begin{tabular}{|c|c|c|c|c|c|c|c|c|c|c|c|c|}
\hline & \multicolumn{2}{|c|}{ Pre-surgery } & \multicolumn{2}{|l|}{3 weeks } & \multicolumn{2}{|l|}{6 weeks } & \multicolumn{2}{|c|}{3 months } & \multicolumn{2}{|c|}{6 months } & \multicolumn{2}{|l|}{1 year } \\
\hline & Flexion & Abduction & Flexion & Abduction & Flexion & Abduction & Flexion & Abduction & Flexion & Abduction & Flexion & Abduction \\
\hline PRP & 126.18 & 126.18 & 55.88 & 51.76 & 101.47 & 97.65 & 131.18 & 119.41 & 142.06 & 137.06 & 152.81 & 153.13 \\
\hline P-value & $\begin{array}{l}\mathrm{p}= \\
0.160\end{array}$ & $\begin{array}{l}\mathrm{p}= \\
0.155\end{array}$ & $\begin{array}{l}p= \\
0.763\end{array}$ & $\begin{array}{l}p= \\
0.676\end{array}$ & $\begin{array}{l}\mathrm{p}= \\
0.402\end{array}$ & $\begin{array}{l}\mathrm{p}= \\
0.484\end{array}$ & $\begin{array}{l}\mathrm{p}= \\
0.577\end{array}$ & $\begin{array}{l}\mathrm{p}= \\
0.252\end{array}$ & $\begin{array}{l}p= \\
0.536\end{array}$ & $\begin{array}{l}p= \\
0.689\end{array}$ & $\begin{array}{l}\mathrm{p}= \\
0.411\end{array}$ & $\begin{array}{l}\mathrm{p}= \\
0.510\end{array}$ \\
\hline
\end{tabular}

Table IV. Contingency table showing imaging tests' scores in both study groups.

\begin{tabular}{|c|c|c|c|c|c|c|c|c|c|c|c|}
\hline & $\begin{array}{l}\text { Ultrasound } \\
\text { (3 months) }\end{array}$ & & & $\begin{array}{l}\text { Ultrasound } \\
\text { (6 months) }\end{array}$ & & & & $\begin{array}{l}\text { MRI } \\
\text { (1 year) }\end{array}$ & & & \\
\hline & $\begin{array}{l}\text { Integer } \\
\text { Tendon }\end{array}$ & $\begin{array}{l}\text { Undetermined } \\
\text { (ORIF) }\end{array}$ & $\begin{array}{l}\text { Partial } \\
\text { tear }\end{array}$ & $\begin{array}{l}\text { Integer } \\
\text { Tendon }\end{array}$ & $\begin{array}{l}\text { Undetermined } \\
\text { ORIF) }\end{array}$ & $\begin{array}{l}\text { Partial } \\
\text { tear }\end{array}$ & $\begin{array}{l}\text { Complete } \\
\text { re-tear }\end{array}$ & $\begin{array}{l}\text { Integer } \\
\text { Tendon }\end{array}$ & $\begin{array}{l}5 \mathrm{~mm} \\
\text { tear }\end{array}$ & $\begin{array}{l}10 \mathrm{~mm} \\
\text { tear }\end{array}$ & $\begin{array}{l}\text { Complete } \\
\text { re-tear }\end{array}$ \\
\hline No PRP & 17 & 0 & 1 & 17 & 0 & 1 & 0 & 16 & 0 & 0 & 2 \\
\hline Total & 33 & 1 & 1 & 32 & 1 & 1 & 1 & 30 & 1 & 1 & 3 \\
\hline
\end{tabular}

ORIF: Open Reduction with Internal Fixation.

- there were no statistically significant differences at 3 weeks $(\mathrm{p}=0.122), 6$ weeks $(\mathrm{p}=0.852), 3$ months $(\mathrm{p}=$ $0.178), 6$ months $(p=0.392)$, or at 1 year $(p=0.223)$ after surgery.

Lastly, we analyzed the imaging tests to check suture's evolution in both groups, using ultrasound at 3 and 6 months post-surgery and MRI at 1 year of follow-up. Both groups were compared, the results presented bellow (Chi-square test) (table IV).

Therefore, comparing re-tear cases in both groups we can conclude that 14 patients from group I and 16 patients from group II did not relapse, whereas 3 patients from group I and 2 from group II showed supraspinatus re-tear; also, these results were not statistically significant ( $\mathrm{p}=0.581$ ) (Chi-square test).

\section{DISCUSSION}

The main goal of PRP administration to a repaired rotator cuff is to improve the tendon's healing process and, thereby, decrease re-tear incidence, considered by some authors to be greater than $25 \%$ of all cases (3).

The administration of platelet concentration levels greater than the physiological ones on the repair site provides extra growth factors that stimulate healing in the suture site (16). However, not all PRP compounds are the same; studies based on fundamental scientific research claim that PRP compounds with high leukocyte levels could trigger a greater unwanted local inflammatory response (18).

A recent study with rabbits (19) demonstrated greater histological healing of a previously tore supraspinatus two months after PRP administration. Despite this experimental data, there is certain controversy in clinical trials published until now, even though there is no evidence consistent enough in favour of PRP therapy in this pathology. According to Via et al. (2), PRP has not been shown to improve healing, rates in rotator cuff tears and the data does not support routine use of PRP in rotator cuff repair.

Baksh et al., in their 31 articles systematic review pointed out that all of them, except for one, presented better healing results with PRP administration (11). Oliva et al. (20), in their systematic review, concluded that there are no differences in clinical outcome after a short period of follow-up after surgical repair.

Other similar studies (21-24) highlighted a lesser re-tear rate. Castricini et al. (25) published, in 2011, the first randomized controlled trial comparing efficacy and safety of PRP augmentation for arthroscopic repair of small and moderate rotator cuff tears with nonaugmented repair of the rotator cuff. These authors concluded that augmentation of the repair with platelet-rich fibrin matrix did not show statistically significant results in shoulder function or structural outcome compared with reparation without augmentation. A recent meta-analysis including 5 randomized studies concluded there is a lesser re-tear rate in those patients included in the PRP groups (15\% vs $30 \%$, respectively; $\mathrm{p}=0.007)(26)$.

Malavolta et al. (27) and Ebert et al. (28) obtained similar results in their studies, published recently and with a similar design to ours (Constant score of 82 in the control group and 82.1 in the experimental group, and 85.2 in the control group vs 86.2 in the PRP group, respectively). 
Paradoxically, we obtained better Constant scores in the control group than in the experimental group. However, these differences were not found to be statistically significant $(\mathrm{p}=0.03)$.

Lastly, we would like to point out that a year after follow-up we found 3 re-tears in the PRP group and 2 in the control group. Malavolta et al. (27) found 1 re-tear in the control group in the first 12 months. Ebert et al. (28) had 4 complete re-tears, 2 in each group. Other works, though without statistically significant differences between groups, had a lesser re-tear rate at the end of the follow-up period $(25,29,30)$. In conclusion, we did not demonstrate, in our study, statistically significant differences comparing both measurements and clinical scales applied during the follow-up period. Perhaps, further randomized control trials with a greater

\section{REFERENCES}

1. Malanga GA, Goldin M. PRP. Review of the current evidence of musculoskeletal conditions. Curr Phys Med Rehab 2014;2(1):1-15.

2. Via AG, De Cupis M, Spoliti M, Oliva F. Clinical and biological aspects of rotator cuff tears. Muscles Ligaments Tendons J 2013 9;3(2):70-9.

3. McElvany MD, McGoldrick E, Gee AO, Nerdaliek MB, et al. Rotator cuff repair: published evidence on factors associated with repair integrity and clinical outcome. Am J Sports Med 2015;43(2):491-500.

4. Burkhart SS, Lo IKY. Arthroscopic rotator cuff repair. J Am Acad Orthop Surg 2006;14(6):333-46.

5. Gamradt SC, Rodeo SA, Warren RF. Platelet rich plasma in rotator cuff repair. Techn Orthop 2007;22(1):26-33.

6. Rodeo SA. Biologic augmentation of rotator cuff tendon repair. J Shoulder Elbow Surg. 2007;16(suppl 5):S191-S197.

7. Gulotta LV, Rodeo SA. Growth factors for rotator cuff repair. Clin Sports Med 2009;28(1):13-23.

8. Anitua E, Andia I, Sanchez M, et al. Autologus preparations rich in growth factors promote proliferation and induce VEGF and HGF production by human tendon cells in culture. J Orthop Res 2005;23:281-6.

9. Zhou Y, Wang J. PRP treatment efficacy for tendinopathy: a review of basic science studies. Biomed Res Int 2016;2016:1-8.

10. Zhang J, Wang JH. Platelet-rich plasma releasate promotes differentiation of tendon stem cells in culture into active tenocyte. AJSM 2010;38(12):2477-86.

11. Baksh N, Hannon CP, Murawski CD, Smyth NA, Kennedy JG. Platelet-rich plasma in tendon models: a systematic review of basic science literature. Arthroscopy 2013;27(8): 1029-35.

12. Wang James H. Can PRP effectively treat injured tendons?. Muscles Ligaments Tendons J 2014;4(1):35-7.

13. Hurley ET, Lim Fat D, Moran CJ, Mullet H. The efficacy of platelet-rich plasma and platelet-rich fibrin in arthroscopic rotator cuff repair: a meta-analysis of randomized controlled trials. Am J Sports Med 2018. sample and a longer follow-up period should be carried out to support these findings.

\section{ACKNOWLEDGEMENTS}

This paper and the research behind it would not have been possible without the support of the FREMAP Mutua de accidentes laborales and Hospital Príncipe de Asturias orthopaedic teams.

\section{CONFLICT OF INTERESTS}

The authors declare that they have no conflict of interests.

14. Verhaegen F, Brys P, Debeer P. Rotator cuff healing after needling of calcific deposit using platelet-rich plasma augmentation: a randomized, prospective clinical trial. J Shoulder Elb Surg 2016;25(2):169-73.

15. Hak A, Rajaratnam K, Ayeni OR, et al. A doublé-blinded placebo randomiced controlled trial evaluating short-term efficacy of platelet-rich plasma in reducing postoperative pain after arthroscopic rotator cuff repair: a pilot study. Sports Health 2015;7(1):58-66.

16. Eppley BL, Woodell JE, Higgins J. Platelet quantification and growth factor analysis from platelet-rich plasma: implications for wound healing. Plast Reconstr Surg 2004;11:1502-1508.

17. Padulo J, Oliva F, Frizziero A, Maffulli N. Basic principles and recommendations in clinical and field Science Research: 2018 update. Muscles Ligaments Tendons J 2018;8(3):305-7.

18. Durant T, Dyment N, McCarthy M, et al. Mesenchymal stem cell response to growth factor treatment and low oxygen tension in 3-dimensional construct environment. Muscles Ligaments Tendons J 2019;04(01):46.

19. Deprés-Tremblay G, Chevrier A, Snow M, et al. Freeze-dried Chitosan-platelet-rich plasma implants improve supraspinatus tendon attachment in a transoseous rotator cuff repair model in the rabbit. J Biomatter Appl 2019;33(6):792-807.

20. Oliva F, Piccirilli E, Bossa M, et al. I.S.Mu.L.T - Rotator cuff tears guidelines. Muscles Ligaments Tendons J 2015;5(4):227-63.

21. Barber FA, Hrnack SA, Snyder SJ, Hapa O. Rotator cuff repair healing influenced by platelet-rich plasma construct augmentation. Arthroscopy 2011;27(8):1029-35.

22. Jo CH, Shin JS, Lee YG, et al. Platelet-rich plasma for arthroscopic repair of large to massive rotator cuff tears: a randomized, single blind, paralell-group trial. Am J Sports Med 2013;41(10):2240-8.

23. Oliva F, Via A, Maffulli N. Role of Growth Factors in Rotator Cuff Healing. Sports Medicine and Arthroscopy Review 2011;19(3):218-26. 
24. Gumina S, Campagna V, Ferrazza G, et al. Use of platelet-leukocyte membrane in arthroscopic repair of large rotator cuff tears. J Bone Joint Surg Am 2012;94(15):1345-52.

25. Castrini R, Longo UG, De Benedetto M, et al. Platelet-rich plasma augmentation for arthroscopic rotator cuff-repair: a randomized controlled trial. Am J Sports Med 2011;39(2)258-65.

26. Cai Y-Z, Zhang C, Lin X-J. Efficacy of platelet-rich plasma in arthroscopic repair of full-thickness rotator cuff tears: a meta-analysis. J Shoulder Elbow Surg 2016;25(8)e248.

27. Malavolta EA, Gracitelli MEC, Assunção JH, Ferreira Neto AA, Bordalo-Rodrigues M, de Camargo OP. Clin- ical and structural evaluations of rotator cuff repair with and without added platelet-rich plasma at 5-year followup. Am J Sports Med 2018;46(13):3134-41.

28. Ebert JR, Wang A, Smith A, et al. A midterm evaluation of postoperative active platelet-rich plasma injections on arthroscopic supraspinatus repair: a randomized controlled trial. Am J Sports Med 2017;45(13):2965-74.

29. Randelli P, Arrigoni P, Ragone V, et al. A prospective RCT study, 2-year follow-up. J Shoulder Elbow Surg 2011;20(4):518-28.

30. Malavolta EA, Graticelli MEC, Ferreira Neto AA, et al. Platelet-rich plasma in rotator cuff repair: a prospective randomized study. Am J Sports Med 2014;42(10)2446-54. 